\title{
ChemComm
}

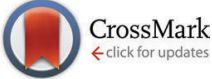

Cite this: Chem. Commun., 2016, 52,5003

Received 30th December 2015, Accepted 3rd March 2016

DOI: $10.1039 / c 5 c c 10643 e$

www.rsc.org/chemcomm

\section{X-ray absorption study of ceria nanorods promoting the disproportionation of hydrogen peroxide $\dagger$}

\author{
Tai-Sing Wu, $\ddagger^{\mathrm{ab}}$ Yunyun Zhou, $\ddagger^{\mathrm{c}}$ Renat F. Sabirianov, ${ }^{\mathrm{d}}$ Wai-Ning Mei, ${ }^{d}$ \\ Yun-Liang Soo*ab and Chin Li Cheung*c
}

A quasi in situ $\mathrm{X}$-ray absorption study demonstrated that the disproportionation of hydrogen peroxide $\left(\mathrm{H}_{2} \mathrm{O}_{2}\right)$ promoted by ceria nanorods was associated with a reversible $\mathrm{Ce}^{3+} / \mathrm{Ce}^{4+}$ reaction and structural transformations in ceria. The direction of this reversible reaction was postulated to depend on the $\mathrm{H}_{2} \mathrm{O}_{2}$ concentration and the fraction of $\mathrm{Ce}^{3+}$ species in ceria nanorods.

Fluorite-structured cerium oxide (or ceria) nanomaterials have attracted great interest from chemistry, materials and engineering communities because of their broad applications in catalysis, ${ }^{1-3}$ sensors, ${ }^{4}$ biomedicine, ${ }^{5}$ and fuel cells. ${ }^{6}$ Ceria has long been known to generate reactive oxygen species by catalyzing the disproportionation of hydrogen peroxide $\left(\mathrm{H}_{2} \mathrm{O}_{2}\right)$. This system has displayed enhanced catalytic activities towards the degradation of pollutants. ${ }^{7,8}$ Ceria nanomaterials have also been reported to scavenge free oxygen radicals and reduce toxic $\mathrm{H}_{2} \mathrm{O}_{2}$ molecules in biological systems. ${ }^{9}$ These chemical properties of ceria nanomaterials have been ascribed to the interconversion of the cerium ions between their +3 and +4 states coupled with the formation of oxygen vacancy defects in ceria. ${ }^{10,11}$ However, this proposed reaction mechanism is still under intense debates..$^{7-9,12}$

The ability to monitor the chemical state transformation of cerium in ceria during reactions is critical to understand the structure-activity relationships of ceria nanomaterials. Currently, the determination of chemical state transformation of cerium in ceria in aqueous reactions is still challenging, largely because of the interference of water molecules in the measurements. X-ray photoelectron spectroscopy (XPS) and UV-Vis spectroscopy have

\footnotetext{
${ }^{a}$ Department of Physics, National Tsing-Hua University, Hsinchu, 30013, Taiwan. E-mail:soo@phys.nthu.edu.tw

${ }^{b}$ National Synchrotron Radiation Research Center, Hsinchu, 30013, Taiwan

${ }^{c}$ Department of Chemistry, University of Nebraska-Lincoln, Lincoln, NE, 68588, USA. E-mail: ccheung2@unl.edu

${ }^{d}$ Department of Physics, University of Nebraska-Omaha, Omaha, NE, 68182, USA $\dagger$ Electronic supplementary information (ESI) available: Experimental details, microstructure and electronic property analysis by TEM, XRD, XPS and XAS. See DOI: $10.1039 / \mathrm{c} 5 \mathrm{cc} 10643 \mathrm{e}$

\# These authors contributed equally.
}

been applied to evaluate changes in the oxidation states of cerium in ceria after its reaction with aqueous $\mathrm{H}_{2} \mathrm{O}_{2}{ }^{12,13}$ However, due to the altered experimental environments such as the vacuum requirement in XPS and limited quantitative capability of UV/Vis spectroscopy, artefacts and misinterpretations in studies using these techniques are often hard to identify.

In situ X-ray absorption spectroscopy (XAS) has been regarded as a versatile tool to elucidate changes in atomic structures and oxidation states of catalysts during reactions. ${ }^{14}$ For example, Wang et al. utilized this technique to illustrate metallic copper in the $\mathrm{Cu} /$ ceria catalyst as the active species in catalyzing the water gas shift reaction. ${ }^{15}$ Quasi in situ XAS techniques have also been applied in catalysis studies to overcome challenges such as chemical compatibility of reactors and strong photon absorption by reactors in the implementations of in situ XAS techniques. ${ }^{14,16}$ For instance, Bergmann et al. applied the quasi in situ XAS technique to reveal reversible structural changes of a crystalline $\mathrm{Co}_{3} \mathrm{O}_{4}$ catalyst in an oxygen evolution reaction. ${ }^{16}$

Herein we report our quasi in situ XAS study of the oxidation states of cerium and the local structures in ceria nanorods upon catalyzing the disproportionation of $\mathrm{H}_{2} \mathrm{O}_{2}$. Ceria nanorods were selected over ceria nanoparticles in this study because they are often reported to have higher catalytic activities. ${ }^{1,17}$ In our XAS experiments, a wet chemical environment enabled by a tris(hydroxymethyl)aminomethane (Tris) buffer solution was employed to prevent the reaction system from drying out and to maintain the $\mathrm{pH}$ of the system. Since the reaction mechanism strongly depends upon the $\mathrm{pH}$ of the reaction, ${ }^{7,18}$ this method allows reliable quantitative evaluation of reaction species in ceria samples. ${ }^{11,19,20}$ Our study revealed reversible changes in the oxidation states of cerium and local atomic structures of ceria in the $\mathrm{H}_{2} \mathrm{O}_{2}$ disproportionation reaction. In our experiments, ceria nanorods were first added to a solution containing $10 \mathrm{mM}$ $\mathrm{H}_{2} \mathrm{O}_{2}$ and $0.1 \mathrm{M}$ Tris buffer $(\mathrm{pH}=7.54)$ to yield a reaction mixture with a nanorod concentration of $500 \mathrm{mg} \mathrm{L}^{-1}$. Samples of this suspended mixture were pipetted out at various reaction times ( $T=10 \mathrm{~min}$ to $10 \mathrm{~h}$ ) to wet filtered papers which were then analyzed by XAS. A control experiment without $\mathrm{H}_{2} \mathrm{O}_{2}$ was used 
for comparisons. These control data were regarded as our data at $T=0 \mathrm{~h}$ (see experimental details in the ESI $\dagger$ ).

The initial morphology, microstructure and chemical state of as-synthesized ceria nanorods ${ }^{1,3}$ were characterized by transmission electron microscopy, X-ray diffraction (XRD) and XPS (see Fig. S1, ESI $\dagger$ ). The ceria nanorods were $50-200 \mathrm{~nm}$ in length and 5-12 $\mathrm{nm}$ in diameter. The XRD pattern of the nanorods was indexed according to the ICDD card 04-013-4361 and was found to display a cubic $F m \overline{3} m$ structure of $\mathrm{CeO}_{2}$. The oxidation states of surface cerium atoms were qualitatively analyzed by XPS. The fraction of $\mathrm{Ce}^{3+}$ on the surface was determined to be $c a .20 \%$, indicating a defective surface structure of this as-synthesized ceria sample (Fig. S3, ESI $\dagger$ ).

X-ray absorption near edge structure (XANES) experiments were performed to investigate the redox behavior of ceria nanorods catalyzing the $\mathrm{H}_{2} \mathrm{O}_{2}$ disproportionation reaction. The Ce $\mathrm{L}_{3}$-edge XANES spectra of ceria nanorods were collected at different reaction times during a $10 \mathrm{~h}$ reaction. Four of the XANES data scanned at the reaction times of $0 \mathrm{~h}, 0.5 \mathrm{~h}, 2 \mathrm{~h}$ and $10 \mathrm{~h}$ are illustrated in Fig. 1. The differences in the intensities of these spectra were demonstrated by the zoomed-in areas of the peaks. The intensity of the XANES spectrum of ceria nanorods significantly decreased in the first $0.5 \mathrm{~h}$. After another $1.5 \mathrm{~h}$ of reaction, the intensity returned to its original magnitude. This was indicated by the XANES data collected at $T=2 \mathrm{~h}$, which had a similar intensity to the one at $T=0 \mathrm{~h}$. As the reaction further proceeded, the XANES spectrum at $T=10 \mathrm{~h}$ demonstrated negligible changes in both the spectral intensity and shape when compared with those at $T=0 \mathrm{~h}$ and $T=2 \mathrm{~h}$.

To reveal the changes in the Ce oxidation state, a quantitative analysis was performed by curve-fitting the XANES spectra with an arctangent function to simulate the edge jump and Gaussian functions for peak features ${ }^{21-23}$ (Fig. 2a). The center of the arctangent function was set at the inflection point of the main edge. Peaks A and B at $5737.7 \mathrm{eV}$ and $5730.8 \mathrm{eV}$ were associated with the $\mathrm{Ce}^{4+}$ ions in ceria, corresponding to the $2 \mathrm{p}^{4} \mathrm{f}^{0} 5 \mathrm{~d}^{*}$ and

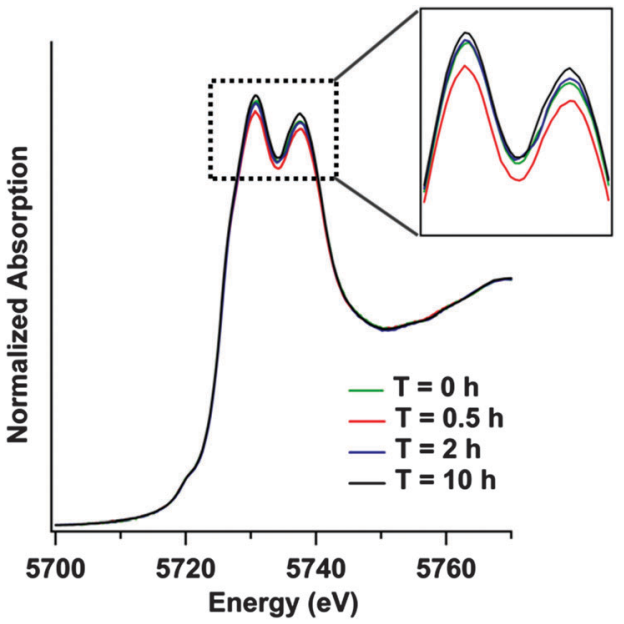

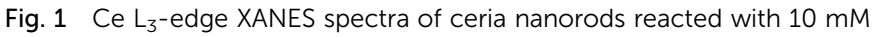
$\mathrm{H}_{2} \mathrm{O}_{2}$ at different reaction times: $T=0 \mathrm{~h}, 0.5 \mathrm{~h}, 2 \mathrm{~h}$ and $10 \mathrm{~h}$. (inset) Zoomed-in peak areas.
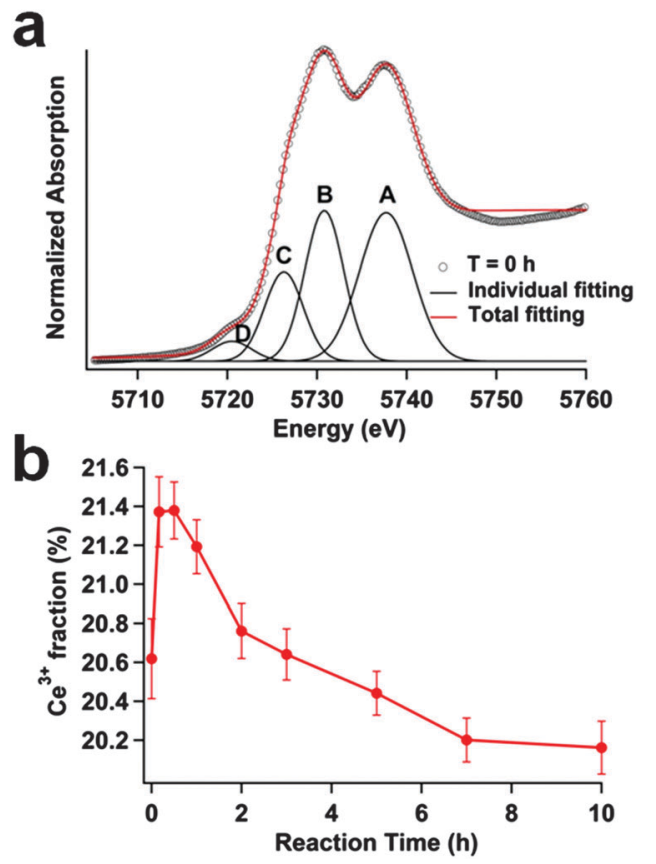

Fig. 2 Quantitative analysis of quasi in situ characterization of ceria nanorods. (a) $\mathrm{Ce} \mathrm{L}_{3}$-edge XANES spectrum and fitting peaks of ceria nanorods in $0.1 \mathrm{M}$ Tris buffer solution without $\mathrm{H}_{2} \mathrm{O}_{2}$. Peaks $A$ and $B$ were ascribed to the $\mathrm{Ce}^{4+}$ state. Peak $\mathrm{C}$ was due to the $\mathrm{Ce}^{3+}$ state. Peak D was assigned to the final states of $2 \mathrm{p} 4 \mathrm{f}^{\star}$. (b) $\mathrm{Ce}^{3+}$ fraction in ceria nanorods as a function of reaction time in the $10 \mathrm{mM} \mathrm{H}_{2} \mathrm{O}_{2} / 0.1 \mathrm{M}$ Tris buffer solution.

$2 \mathrm{p} 4 \mathrm{f}^{1} 5 \mathrm{~d}^{*} \mathrm{~L}$ final states, respectively. While $2 \mathrm{p}$ denotes the hole produced in $2 \mathrm{p}^{3 / 2}, 5 \mathrm{~d}^{*}$ refers to the presence of an excited electron in the $5 \mathrm{~d}$ band, and $\mathrm{L}$ represents a ligand hole in the anion orbital. Peak C, at $5726.3 \mathrm{eV}$, was associated with the $\mathrm{Ce}^{3+}$ valence state. Peak D, located at $5720.5 \mathrm{eV}$ in the pre-edge region, was assigned to the final states of $2 \mathrm{p} 4 \mathrm{f}^{*}$, which was forbidden by the selection rule due to a $5 \mathrm{~d}$ ad-mixture with the 4f state. ${ }^{19,24,25}$ With a delocalized d character at the bottom of the conduction band due to the cubic crystal-field splitting of Ce 4f states, the transition was partially allowed to appear as a small peak. $4 \mathrm{f}^{*}$ referred to the presence of an excited electron in the $4 \mathrm{f}$ band.

The Ce $\mathrm{L}_{3}$-edge XANES spectra of all samples showed the coexistence of $\mathrm{Ce}^{3+}$ and $\mathrm{Ce}^{4+}$ states, with the $\mathrm{Ce}^{4+}$ state being dominant in all samples. The fractions of $\mathrm{Ce}^{3+}$ and $\mathrm{Ce}^{4+}$ in the samples were calculated using the following equations:

$$
\begin{aligned}
& {\left[\mathrm{Ce}^{3+}\right]=\mathrm{A}\left(\mathrm{Ce}^{3+}\right) /\left(\mathrm{A}\left(\mathrm{Ce}^{3+}\right)+\mathrm{A}\left(\mathrm{Ce}^{4+}\right)\right)} \\
& {\left[\mathrm{Ce}^{4+}\right]=\mathrm{A}\left(\mathrm{Ce}^{4+}\right) /\left(\mathrm{A}\left(\mathrm{Ce}^{3+}\right)+\mathrm{A}\left(\mathrm{Ce}^{4+}\right)\right)}
\end{aligned}
$$

where $\mathrm{A}\left(\mathrm{Ce}^{3+}\right)$ and $\mathrm{A}\left(\mathrm{Ce}^{4+}\right)$ were the total integrated peak areas corresponding to the $\mathrm{Ce}^{3+}$ and $\mathrm{Ce}^{4+}$ XANES signals, respectively. According to Fig. 2b, the $\mathrm{Ce}^{3+}$ fraction (expressed in percentage) in ceria nanorods increased from $20.6 \%$ at $T=0 \mathrm{~h}$ to $21.4 \%$ at $T=0.5 \mathrm{~h}$. It then slowly decreased to $20.8 \%$ at $T=2 \mathrm{~h}$. After a 3 h-reaction, the $\mathrm{Ce}^{3+}$ fraction approached $20.6 \%$, which was very similar to its original value. During the reaction period between $3 \mathrm{~h}$ and $10 \mathrm{~h}$, the overall percentage of $\mathrm{Ce}^{3+}$ kept 
decreasing but varied insignificantly. It stayed at around the level of $20.2 \%$ at the end of reaction. Note that the changes in the $\mathrm{Ce}^{3+}$ fraction detected by XANES were not likely due to the adsorption of Ce ions from the dissolution of ceria onto ceria nanorods. Our inductively coupled plasma-mass spectrometry studies concluded that the concentration of Ce ions in the reaction mixtures was less than $1 \mathrm{ppb}$ (see details in the ESI $\dagger$ ).

In summary, during the $10 \mathrm{~h}$ long $\mathrm{H}_{2} \mathrm{O}_{2}$ disproportionation reaction, the surface $\mathrm{Ce}^{4+}$ of ceria nanorods was reduced to $\mathrm{Ce}^{3+}$ by the $\mathrm{H}_{2} \mathrm{O}_{2}$ molecules in the beginning of the first $0.5 \mathrm{~h}$, and then was slowly oxidized back to $\mathrm{Ce}^{4+}$ in the next $9 \mathrm{~h}$. The surface reaction in aqueous solutions was governed by the surface potential and the overall redox potential of ceria and $\mathrm{H}_{2} \mathrm{O}_{2} \cdot{ }^{9}$ High concentration of $\mathrm{H}_{2} \mathrm{O}_{2}$ exhibited high reduction potential and thus was expected to reduce surface $\mathrm{Ce}^{4+}$ to $\mathrm{Ce}^{3+}$ at the beginning. The slow oxidative process of ceria was likely due to the oxidizing power of $\mathrm{H}_{2} \mathrm{O}_{2}$, which became dominant after a dramatic decrease of $\mathrm{H}_{2} \mathrm{O}_{2}$ concentration in the solution. In addition, the defective ceria surface with high concentration of $\mathrm{Ce}^{3+}$ decreased the reduction potential of the ceria surface, and was postulated to enable ceria to be oxidized by $\mathrm{H}_{2} \mathrm{O}_{2}$.

Local structures surrounding Ce atoms were probed using the extended X-ray absorption fine structure (EXAFS) technique. The experimental data were analyzed using the IFEFFIT software package. $^{26}$ The Fourier transforms of Ce $\mathrm{L}_{3}$-edge $k^{3}$-weighted $\chi(k)$ of EXAFS spectra depicted the changes in the local structure of Ce atoms with respect to the reaction time (Fig. 3 and Fig. S4, ESI $\dagger$ ). The fitting parameters of EXAFS spectra are shown in Table 1 and Table S1 (ESI $\dagger$ ). The as-synthesized ceria nanorods exhibited a coordination number of 5.8 in the first $\mathrm{Ce}-\mathrm{O}$ shell. An extra peak appeared at around $1.65 \AA$ after the addition of hydrogen peroxide. Owing to the "shortness" of this $R$ value, this peak could be attributed to the presence of superficial chemical structures with a $\mathrm{Ce}=\mathrm{O}$ bond, possibly similar to the one reported in a cerium(Iv) oxo complex, $\left[\mathrm{Ce}=\mathrm{O}\left(\mathrm{L}_{\mathrm{OEt}}\right)_{2}\left(\mathrm{H}_{2} \mathrm{O}\right)\right] \cdot \mathrm{MeC}(\mathrm{O}) \mathrm{NH}_{2} \cdot{ }^{27}$

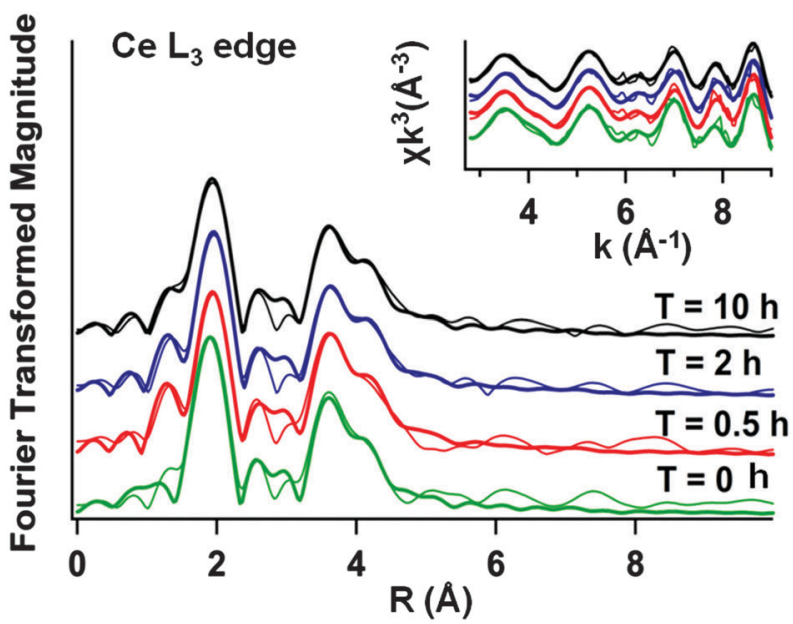

Fig. 3 Fourier transformed $\mathrm{Ce}_{3}$-edge EXAFS data of ceria nanorod sample with different reaction times in $10 \mathrm{mM} \mathrm{H} \mathrm{O}_{2} / 0.1 \mathrm{M}$ Tris buffer solution. The inset shows the corresponding EXAFS spectra in $k$-space. Data: thick lines; fittings: thin lines.
This peak attained its highest intensity at $T=0.5 \mathrm{~h}$. The intensity then slowly decreased after $2 \mathrm{~h}$ reaction time until $T=10 \mathrm{~h}$. This trend was consistent with the changes in $\mathrm{Ce}^{3+}$ fraction from XANES data analysis, indicating the modification of local structures caused by reactions with $\mathrm{H}_{2} \mathrm{O}_{2}$. The coordination number of the $\mathrm{Ce}-\mathrm{O}$ bond at $2.34 \AA$ reached its minimum value of 4.7 at $T=0.5$ and $2 \mathrm{~h}$, and slowly increased to 5.8 at $T=10 \mathrm{~h}$, which was closer to that of ceria samples before reaction (i.e. at $T=0 \mathrm{~h}$ ).

The redox cycle of the ceria sample revealed by the EXAFS data agreed well with the intensity changes in the XANES data, implying a reduction-and-oxidation cycle of ceria with $\mathrm{H}_{2} \mathrm{O}_{2}$ during the $10 \mathrm{~h}$ reaction. Based on our XANES and EXAFS results, we proposed that ceria underwent a redox cycle process in the Fenton-like reaction with $\mathrm{H}_{2} \mathrm{O}_{2}$ as follows:

Ceria reduction process:

$$
\mathrm{Ce}^{4+}+\mathrm{H}_{2} \mathrm{O}_{2} \rightarrow \mathrm{Ce}^{3+}+\mathrm{HO}_{2}^{\bullet}+\mathrm{H}^{+}
$$

Ceria oxidation processes:

$$
\begin{gathered}
2 \mathrm{Ce}^{3+}+\mathrm{H}_{2} \mathrm{O}_{2}+2 \mathrm{H}^{+} \rightarrow 2 \mathrm{Ce}^{4+}+2 \mathrm{H}_{2} \mathrm{O} \\
4 \mathrm{Ce}^{3+}+\mathrm{O}_{2}+4 \mathrm{H}^{+} \rightarrow 4 \mathrm{Ce}^{4+}+2 \mathrm{H}_{2} \mathrm{O}
\end{gathered}
$$

In a concentrated $\mathrm{H}_{2} \mathrm{O}_{2}$ solution, $\mathrm{H}_{2} \mathrm{O}_{2}$ molecules were proposed to serve as reducing agents and convert the surface $\mathrm{Ce}^{4+}$ to $\mathrm{Ce}^{3+}$, resulting in the increase of $\mathrm{Ce}^{3+}$ fraction and the decrease of an average coordination number of oxygen atoms around Ce atoms at $2.34 \AA$.

The hydroperoxyl radical $\left(\mathrm{HO}_{2}^{\bullet}\right)$ byproduct in eqn (1) was known to involve in the conversion of the Ce oxidation state in ceria. $^{7,28}$ Besides the reaction species described in eqn (1), other reactive oxygen species such as $\mathrm{O}_{2}{ }^{\bullet},{ }^{1} \mathrm{O}_{2}, \mathrm{O}_{2}{ }^{-}$and $\mathrm{OH}^{\bullet}$ had been proposed to form in the reduction reaction. ${ }^{7,9,11}$ These unstable oxygen species could undergo interconversions with each other through electron transfers. Overall, these species altered the surface coordination and chemical potential of ceria, and therefore regulated the chemical states of cerium in ceria

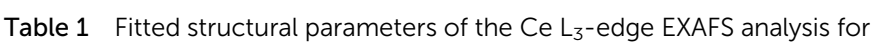
ceria nanorod samples reacting with $10 \mathrm{mM} \mathrm{H}_{2} \mathrm{O}_{2} / 0.1 \mathrm{M}$ Tris buffer solution. $N$ is the coordination number around the central atoms. $R$ is the average bond distance. $\sigma^{2}$ is the Debye-Waller factor. Italic marks indicate fixed parameters in the fitting analysis

\begin{tabular}{lllll}
\hline $\begin{array}{l}\text { Ceria nanorods } \\
\text { reaction time }\end{array}$ & Atom & $N$ & $R(\AA)$ & $\sigma^{2}\left(10^{-3} \AA^{2}\right)$ \\
\hline$T=0 \mathrm{~h}$ & $\mathrm{O}$ & $5.8 \pm 0.6$ & $2.30 \pm 0.01$ & $4.7 \pm 1.2$ \\
& $\mathrm{Ce}$ & $5.6 \pm 0.4$ & 3.83 & $1.8 \pm 0.6$ \\
$T=0.5 \mathrm{~h}$ & $\mathrm{O}$ & $0.9 \pm 0.3$ & $1.65 \pm 0.02$ & $3.9 \pm 0.8$ \\
& $\mathrm{O}$ & $4.7 \pm 0.4$ & $2.32 \pm 0.01$ & $3.9 \pm 0.8$ \\
& $\mathrm{Ce}$ & $4.7 \pm 0.4$ & 3.83 & $1.3 \pm 0.3$ \\
$T=2 \mathrm{~h}$ & $\mathrm{O}$ & $0.7 \pm 0.2$ & $1.66 \pm 0.02$ & $3.6 \pm 0.8$ \\
& $\mathrm{O}$ & $4.7 \pm 0.3$ & $2.33 \pm 0.01$ & $3.6 \pm 0.8$ \\
& $\mathrm{Ce}$ & $4.5 \pm 0.3$ & 3.83 & $0.6 \pm 0.4$ \\
$T=10 \mathrm{~h}$ & $\mathrm{O}$ & $0.7 \pm 0.3$ & $1.68 \pm 0.03$ & $6.6 \pm 0.8$ \\
& $\mathrm{O}$ & $5.8 \pm 0.4$ & $2.33 \pm 0.01$ & $6.6 \pm 0.8$ \\
& $\mathrm{Ce}$ & $4.9 \pm 0.3$ & 3.83 & $1.1 \pm 0.4$
\end{tabular}


nanorods during the reaction. A slight reduction of its $\mathrm{pH}$ value from 7.54 to 7.41 in this system was observed after the first $10 \mathrm{~min}$ of the reaction. This finding supported our hypothesis that $\mathrm{Ce}^{4+}$ in ceria were reduced to $\mathrm{Ce}^{3+}$ by $\mathrm{H}_{2} \mathrm{O}_{2}$ and $\mathrm{H}_{3} \mathrm{O}^{+}$were produced in this reaction. Our finding corroborated similar observations of $\mathrm{pH}$ reduction by Wang et al. in their study of $\mathrm{H}_{2} \mathrm{O}_{2}$ disproportionation catalyzed by nanoceria. ${ }^{11}$

As the reaction proceeded, the concentration of $\mathrm{H}_{2} \mathrm{O}_{2}$ decreased and ceria nanorods possessed significant population of $\mathrm{Ce}^{3+}$ on their surfaces. These two factors led to changes in solution potential and ceria surface potential, which consequently promoted the oxidation of $\mathrm{Ce}^{3+}$ to $\mathrm{Ce}^{4+}$ by $\mathrm{H}_{2} \mathrm{O}_{2}$ molecules (eqn (2)). During the $\mathrm{H}_{2} \mathrm{O}_{2}$ decomposition process, a lot of bubbles which were ascribed to oxygen evolution were observed. This increased the partial pressure of oxygen which could also oxidize the ceria surface (eqn (3)). Overall, these factors possibly gave rise to the decrease in the $\mathrm{Ce}^{3+}$ fraction and an increase in the $\mathrm{Ce}-\mathrm{O}$ coordination number at $2.3 \AA$ as indicated by our EXAFS data. Furthermore, the coordinatively unsaturated Ce sites, which were indirectly inferred from the increase in $\mathrm{Ce}^{3+}$ fraction, might also provide reactive sites for the adsorption of peroxide species and participate in the disproportionation of $\mathrm{H}_{2} \mathrm{O}_{2}$ molecules. ${ }^{11}$

Our hypothesized redox cycle could also be conjectured from the reported Pourbaix diagram of the $\mathrm{Ce}(\mathrm{III} / \mathrm{IV})-\mathrm{H}_{2} \mathrm{O}-\mathrm{H}_{2} \mathrm{O}_{2}$ aqueous system. ${ }^{29}$ Depending on the $\mathrm{pH}$ of solutions, $\mathrm{H}_{2} \mathrm{O}_{2}$ concentration and the surface potential of ceria, $\mathrm{H}_{2} \mathrm{O}_{2}$ could exhibit dual behavior, either acting as an oxidizing agent or a reducing agent. ${ }^{29}$ The standard potentials of $\mathrm{H}_{2} \mathrm{O}_{2} / \mathrm{HO}_{2}{ }^{\bullet}$ and $\mathrm{Ce}^{4+} / \mathrm{Ce}^{3+}$ are $1.5 \mathrm{~V}$ and $1.44 \mathrm{~V}$, respectively. ${ }^{28}$ The similarity of these two electrochemical potentials potentially permitted the reversible reaction (eqn (1)-(3)) to occur because the concentration of $\mathrm{H}_{2} \mathrm{O}_{2}$ and the $\mathrm{Ce}^{3+}$ fraction of the nanorod surface changed during the catalyzed reaction.

To summarize, we demonstrated the application of a quasi in situ XAS technique to elucidate the changes in chemical states of cerium and local structures in ceria nanorods in their reaction with $\mathrm{H}_{2} \mathrm{O}_{2}$. Our measurements under wet conditions allowed reliable analysis of chemical states of cerium and the structures in ceria due to minimal environmental modifications and disturbance to the ceria nanorods. The observed reversible structural changes of ceria nanorods were strongly correlated with the $\mathrm{Ce}^{3+} / \mathrm{Ce}^{4+}$ conversion and changes in the $\mathrm{H}_{2} \mathrm{O}_{2}$ concentration.

The authors are grateful for the financial support from the National Science Foundation (CHE-1362916). We acknowledge the National Synchrotron Radiation Research Center, Nebraska Center of Materials and Nanoscience, Cornell Center for Materials Research and Rare Earth Salts for the use of their facilities.

\section{Notes and references}

1 N. J. Lawrence, J. R. Brewer, L. Wang, T. S. Wu, J. Wells-Kingsbury, M. M. Ihrig, G. H. Wang, Y. L. Soo, W. N. Mei and C. L. Cheung, Nano Lett., 2011, 11, 2666-2671.

2 Y. Zhou, N. J. Lawrence, L. Wang, L. M. Kong, T. S. Wu, J. Liu, Y. Gao, J. R. Brewer, V. K. Lawrence, R. F. Sabirianov, Y. L. Soo, X. C. Zeng, P. A. Dowben, W. N. Mei and C. L. Cheung, Angew. Chem., Int. Ed., 2013, 52, 6936-6939.

3 Y. Zhou, N. J. Lawrence, T. S. Wu, J. Liu, P. Kent, Y. L. Soo and C. L. Cheung, ChemCatChem, 2014, 6, 2937-2946.

4 N. Izu, S. Nishizaki, W. Shin, T. Itoh, M. Nishibori and I. Matsubara, Sensors, 2009, 9, 8884-8895.

5 C. Xu and X. G. Qu, NPG Asia Mater., 2014, 6, e90.

6 S. D. Park, J. M. Vohs and R. J. Gorte, Nature, 2000, 404, 265-267.

7 P. F. Ji, L. Z. Wang, F. Chen and J. L. Zhang, ChemCatChem, 2010, 2, 1552-1554.

8 Y. C. Wang, X. X. Shen and F. Chen, J. Mol. Catal. A: Chem., 2014, 381, 38-45.

9 S. M. Hirst, A. S. Karakoti, R. D. Tyler, N. Sriranganathan, S. Seal and C. M. Reilly, Small, 2009, 5, 2848-2856.

10 C. Walkey, S. Das, S. Seal, J. Erlichman, K. Heckman, L. Ghibelli, E. Traversa, J. F. McGinnis and W. T. Self, Environ. Sci.: Nano, 2015, 2, 33-53.

11 Y. J. Wang, H. Dong, G. M. Lyu, H. Y. Zhang, J. Ke, L. Q. Kang, J. L. Teng, L. D. Sun, R. Si, J. Zhang, Y. J. Liu, Y. W. Zhang, Y. H. Huang and C. H. Yan, Nanoscale, 2015, 7, 13981-13990.

12 J. M. Perez, A. Asati, S. Nath and C. Kaittanis, Small, 2008, 4, 552-556.

13 M. Das, S. Patil, N. Bhargava, J. F. Kang, L. M. Riedel, S. Seal and J. J. Hickman, Biomaterials, 2007, 28, 1918-1925.

14 A. I. Frenkel, J. A. Rodriguez and J. G. G. Chen, ACS Catal., 2012, 2, 2269-2280.

15 X. Wang, J. A. Rodriguez, J. C. Hanson, D. Gamarra, A. MartínezArias and M. Fernández-García, J. Phys. Chem. B, 2006, 110, 428-434.

16 A. Bergmann, E. Martinez-Moreno, D. Teschner, P. Chernev, M. Gliech, J. F. de Araujo, T. Reier, H. Dau and P. Strasser, Nat. Commun., 2015, 6, 8625.

17 X. Du, D. Zhang, L. Shi, R. Gao and J. Zhang, J. Phys. Chem. C, 2012, 116, 10009-10016.

18 P. Salgado, V. Melin, D. Contreras, Y. Moreno and H. D. Mansilla, J. Chil. Chem. Soc., 2013, 58, 2096-2101.

19 A. M. Shahin, F. Grandjean, G. J. Long and T. P. Schuman, Chem. Mater., 2005, 17, 315-321.

20 F. Zhang, P. Wang, J. Koberstein, S. Khalid and S. W. Chan, Surf. Sci., 2004, 563, 74-82.

21 R. C. Karnatak, J. M. Esteva and H. Dexpert, Phys. Rev. B: Condens. Matter Mater. Phys., 1987, 36, 1745-1749.

22 H. Dexpert, R. C. Karnatak, J. M. Esteva, J. P. Connerade, M. Gasgnier, P. E. Caro and L. Albert, Phys. Rev. B: Condens. Matter Mater. Phys., 1987, 36, 1750-1753.

23 A. Bianconi, A. Marcelli, H. Dexpert, R. Karnatak, A. Kotani, T. Jo and J. Petiau, Phys. Rev. B: Condens. Matter Mater. Phys., 1987, 35, 806-812.

24 F. F. Munoz, L. M. Acuna, C. A. Albornoz, A. G. Leyva, R. T. Baker and R. O. Fuentes, Nanoscale, 2015, 7, 271-281.

25 G. Kaindl, G. Schmiester, E. V. Sampathkumaran and P. Wachter, Phys. Rev. B: Condens. Matter Mater. Phys., 1988, 38, 10174-10177.

26 M. Newville, J. Synchrotron Radiat., 2001, 8, 322-324.

27 Y. M. So, G. C. Wang, Y. Li, H. H. Y. Sung, I. D. Williams, Z. Y. Lin and W. H. Leung, Angew. Chem., Int. Ed., 2014, 53, 1626-1629.

28 P. B. Sigler and B. J. Masters, J. Am. Chem. Soc., 1957, 79, 6353-6357.

29 P. Yu, S. A. Hayes, T. J. O'Keefe, M. J. O'Keefe and J. O. Stoffer, J. Electrochem. Soc., 2006, 153, C74-C79. 